\title{
Acesso à leitura e remição de pena no Brasil: uma análise crítica visando a agenda 2030 da ONU
}

\author{
Yara Maria Silva Cinque \\ Universidade Estadual Paulista "Júlio Mesquita Filho", Brasil \\ Carlos Cândido de Almeida \\ Universidade Estadual Paulista "Júlio de Mesquita Filho", Brasil
}

COMMUNICATIONS

\begin{abstract}
Resumo
A leitura é um importante mecanismo para o desenvolvimento humano, pois possibilita que o indivíduo consiga compreender e interpretar o mundo e os símbolos que o cercam. De forma que o acesso deve ser para todas as pessoas, não julgando se está livre ou reclusa de liberdade. A realidade de acesso e mediação de leitura no Brasil enfrenta problemas por conta da crise no sistema carcerário. Problemas que vão desde a falta de bibliotecas até a não abrangência de projetos de leitura em todos os estabelecimentos penitenciários. No ambiente prisional o país ainda encontra com dificuldades estruturais e políticas para disponibilizar o acesso à leitura aos internos, mesmo depois de 34 anos da Lei de Execução Penal (LEP) 7.210 de 11 de julho de 1984, para a criação de bibliotecas prisionais São poucas unidades que contém uma biblioteca em suas instalações,como a falta de profissional adequado para atuar no local. No entanto, para apenado ter acesso à leitura, educação e trabalho o estado brasileiro criou as leis de remição de pena como uma forma de ressocialização do sujeito. A remição de pena pela a leitura começou por meio de uma iniciativa da Penitenciária Federal de Catanduvas no estado do Paraná, no qual foi aderido por outras instituições penitenciárias de âmbito federal. Em 2013 o Conselho Nacional de Justiça (CNJ) realizou diretrizes para a remição de pena por meio da leitura. Porém, mesmo com iniciativas ainda há uma lacuna entre os reclusos no acesso à leitura e educação. No entanto, esta pesquisa é de natureza bibliográfica na qual foi feito revisão de literatura e levantamento de leis Federais, Estaduais, como diretrizes federais relacionadas ao acesso à leitura em unidades prisionais, no que concerne ao cumprimento dos objetivos propostos pela Organização das Nações Unidas (ONU) para o Desenvolvimento Sustentável - Agenda 2030, principalmente no objetivo 16. Após a criação das orientações do CNJ, alguns estados brasileiros criaram suas próprias leis de remição de leitura, outros estados decidiram criar somente projetos de leitura, até o momento não existe uma lei federal relacionada ao assunto. Não podemos esquecer que, o sistema carcerário e o poder público encontram-se em crise, nesse sentido, é equivocado criar expectativas que somente com a remição de pena o aprisionado será ressocializado. Da mesma maneira, não podemos criar expectativa na Biblioteconomia que até o momento não possui uma literatura que examine a remição de pena pela perspectiva da área.
\end{abstract}

Palavras-chave:

Acesso à leitura; Agenda 2030 da ONU; Leitura em unidades prisionais; Remição de pena.

\section{Access to reading and redemption in Brazil: a critical analysis aimed at the UN 2030 agenda}

\begin{abstract}
Reading is an important mechanism for human development because it allows the individual to understand and interpret the world and the symbols that surround it. Thus, access must be for all people, not judging whether they are free or free. The reality of access and mediation of reading in Brazil faces problems due to the crisis in the prison system. Problems ranging from the lack of libraries to the lack of reading projects in all prisons. In the prison environment, the country still faces structural and political difficulties in making access to reading accessible to inmates even after 34 years of the Penal Enforcement Act (LEP) 7,210, dated 11 July 1984, for the creation of penitentiary libraries. There are only a few units that contain a library on their premises, such as the lack of proper professionals to operate on the premises. However, in order to have access to reading, education and work, the Brazilian State created the laws of redemption of punishment as a way of resocialization of the subject. The sentence to retrieve the reading was initiated by the Federal Penitentiary of Catanduvas, in the state of Paraná, where it was joined by other penitentiary institutions of federal scope. In 2013, the National Council of Justice (CNJ) conducted guidelines for the remission of sentences through reading. However, even with initiatives, there is still a gap between prisoners in access to reading and education. This research is of a bibliographical nature, in which a review of the literature and survey of the federal state legislations, as federal guidelines related to access to reading in penitentiary units, is carried out, in the accomplishment of the goals proposed by the United Nations Organization for Sustainable Development - Agenda 2030, mainly in objective 16. After the creation of the guidelines of the CNJ, some Brazilian states created their own laws of recovery of reading, other states decided to create only reading projects, so far there is no federal law related to the subject. We can not forget that the prison system and the public power are in crisis, in this sense, it is wrong to create expectations that only with the remission of prisoners will be re-socialized. In the same way, one should not create expectation in the Librarianship that until the moment does not have a literature that examines the redemption of the penalty from the perspective of the area.
\end{abstract}

Keywords:

Reading access; Penalty remission; Reading in prisons; UN Agenda 2030. 


\section{Introdução}

A leitura promove o ser humano a possibilidade de compreender o mundo a sua volta, os símbolos inseridos naquela realidade, como também ajuda o desenvolvimento intelectual do sujeito. Segundo Martins (1988, p. 33), o ato da leitura se "realiza a partir do diálogo do leitor com o objeto lido - seja escrito, sonoro, seja um gesto, uma imagem, um acontecimento".

Ler desenvolve a compreensão de uma realidade e de símbolos que caracteriza uma população, considerando que todos, sem discriminação, devem ter acesso a materiais de leitura, não levando em conta sua condição financeira, social, racial e, principalmente, se o indivíduo está em condição de encarceramento.

A leitura pressupõe a compreensão de mundo, o entendimento de signos linguísticos, a interação com uma comunidade, entre outros fatores. Para Yunes (1995) ler é um "ato de sensibilidade e da inteligência, de compreensão e de comunhão com o mundo; lendo expandimos o estar no mundo alcançamos esferas do conhecimento antes não experimentadas."

Isto é, o ato de ler está interligada com a vida humana de maneira que para o homem evoluir intelectualmente é necessário que se utilize desse mecanismo ou instrumento de emancipação social, se assim pode ser chamado para prosseguir. A leitura pode ser considerado "um instrumento de poder, a leitura vem através dos tempos assumindo seu papel na sociedade, que é o de contribuir como decodificadora de signos" (NEVES, 1998). Seu papel é fundamental na sociedade, levando-se em conta que a leitura é uma das bases para o desenvolvimento humano, pois o indivíduo aprende desde o nascimento a compreender o ambiente que o cerca. Segundo Silva (2011) argumenta que a "leitura é um processo de compreensão de mundo que envolve características essenciais singulares do homem, levando a sua capacidade simbólica e de interação com outra palavra de mediação marcada no contexto social."

A realidade brasileira de acesso e disseminação da leitura, tanto para pessoas em condição de liberdade para ir e vir quanto as reclusas está longe de ser a ideal. O país sofre as consequências por não promover políticas públicas de acesso à informação e aos materiais de leitura. O número de bibliotecas públicas, escolares e prisionais são insuficientes para implementar estas políticas.

Essas instituições também enfrentam dilemas como: falta de profissional capacitado, falta de materiais, equipamentos e local apropriado, entre tantos outros problemas. As bibliotecas escolares, por exemplo, se encontram em uma situação precária, de forma que são poucas as escolas públicas que dispõem de uma biblioteca de qualidade. Uma alternativa paliativa foi a criação de salas de leitura como resposta à Lei de № 12.244 de 24 de maio de 2010, que estabeleceu um prazo de 10 anos para que todas as escolas brasileiras disponham de bibliotecas.

As pessoas reclusas, por exemplo, mesmo estando confinadas e com liberdade de ir e vir restringida têm direitos ao acesso à informação e a praticar a leitura, de forma a produzir a sensação de lazer e liberdade em um ambiente sufocante. Os diferentes tipos de espaços de leitura existentes em presídios no Brasil ainda estão longe de serem ideias para atenderem os diferentes perfis de usuários.

As bibliotecas prisionais se encontram em uma situação pior do que as bibliotecas escolares e públicas. Mesmo sendo previsto pela Lei de Execução Penal (LEP) 7.210 de 11 de julho de 1984, em seu artigo $21^{\circ}$, que em atendimento "às condições locais, dotar-se-á cada estabelecimento de uma biblioteca, para uso de todas as categorias de reclusos, provida de livros instrutivos, recreativos e didáticos". Porém atualmente não são todas as unidades prisionais que dispõem de uma biblioteca de qualidade. Estes espaços poderiam auxiliar na educação, lazer e desenvolvimento do senso crítico desses cidadãos.

Sabendo do potencial da leitura para a promoção da cidadania e garantia de reinserção dos detentos à sociedade, foi criada a possibilidade da remição da pena pela leitura de livros. Esse instrumento de reintegração à sociedade começou a ser conhecida no país em 2009 com um projeto estadual, que englobava somente a população de uma Penitenciária Federal de Catanduvas no Estado do Paraná, Região Sul do Brasil. Os projetos de remição de pena tratam de permitir o acesso aos presos a obras literárias que, depois de lidas e fichadas, possibilitam a redução da pena de alguns tipos de crime. Conforme as unidades prisionais de outros estados da federação se interessavam pelo projeto, houve a necessidade de emissão de algumas diretrizes para execução dos processos.

Sendo assim, em 2013, o Conselho Nacional de Justiça (CNJ) criou a Resolução de № 44, que estabelece regras claras para o desenvolvimento de um projeto de leitura de remição de pena. Alguns estados brasileiros criaram 
leis para regulamentar, outros somente idealizaram projetos seguindo as normas do CNJ. Essa atividade seria uma ferramenta para remição, como também uma forma de tentar ressocializar o indivíduo, porém será que essa ferramenta jurídica ocorre efetivamente ou somente é uma forma de diminuir a pena sem se preocupar com o avanço intelectual e a ressocialização dos sujeitos. Os projetos de leitura e remição de pena veem como uma solução provisória para a lacuna existente entre a leitura e a educação dos apenados. Este trabalho busca resumir as iniciativas brasileiras de remição da pena através da leitura como forma de atender ao objetivo lançado pela Organização das Nações Unidas na agenda 2030 para o desenvolvimento sustentável, especificamente o objetivo 16, "Promover sociedades pacíficas e inclusivas para o desenvolvimento sustentável, proporcionar o acesso à justiça para todos e construir instituições eficazes, responsáveis e inclusivas em todos os níveis" (ORGANIZAÇÃO DAS NAÇÕES UNIDAS DO BRASIL, 2015).

\section{A Remição de pena pela leitura no Brasil}

Antes de mencionar os projetos de acesso à leitura como forma de remição da pena, devemos entender que o acesso à leitura é um direito garantido pelas Regras Mínimas das Nações Unidas para Tratamento de Presos (Regras de Mandela) de 2016, em que se garante na regra 63 que os:

\footnotetext{
presos devem ser regularmente informados sobre os assuntos mais importantes dos noticiários, por meio de leitura de jornais, de periódicos ou de publicações institucionais especiais, por transmissões sem fio, por palestras ou por quaisquer meios similares autorizados ou controlados pela administração prisional.
}

Os projetos de leitura em prisões nacionais começaram em 2009 em uma unidade prisional de âmbito federal localizada no Estado do Paraná. Após a iniciativa da Penitenciária de Catanduvas outras dois estabelecimentos prisionais federais adotaram projetos de leitura, a saber: Penitenciária de Campo Grande, no estado do Mato Grosso do Sul, em 2010 e a Penitenciária de Porto Velho, em Rondônia, em 2012. Em 2012, a Corregedoria Geral da Justiça Federal por meio da Portaria Conjunta de $n^{\circ} 276$ de 20, de junho de 2012, estabeleceu normas para as unidades que estivessem interessadas em desenvolver iniciativas, desde que os apenados participassem de forma voluntária e a unidade fosse provida de um acervo que contenha 20 exemplares de cada livro.

Somente em 2011 foi aprovada a lei com o intuito de se remir a pena pelo trabalho e estudo, como prevê na Lei de $n^{\circ}$ 12.433, de 29 de julho de 2011, que modifica os artigos 126, 127, 128 e 129 da Lei de Execução Penal (LEP) e garante a remição pelo estudo convertendo um dia da pena para cada 3 dias frequentados com 12 horas de atividade. Já no caso do preso trabalhar, o mesmo consegue diminuir um dia da pena por 3 dias trabalhados. Contudo, a remição de pena pela leitura surge da iniciativa do Estado do Paraná com a Lei Estadual 17.329, de 8 de outubro de 2012 que institui o projeto 'Remição pela Leitura' nas unidades prisionais de todo o estado. 0 artigo 2 assim apresenta: "O Projeto 'Remição pela Leitura' tem como objetivo oportunizar aos presos custodiados alfabetizados o direito ao conhecimento, à educação, à cultura e ao desenvolvimento da capacidade crítica, por meio da leitura e da produção de relatórios de leituras e resenhas." (PARANÁ, 2012)

O projeto complementaria a Lei da Remição de Pena pelo estudo, neste caso não foi elaborado uma diretriz que diferencie estudo de leitura. O encarcerado que estiver no Ensino Fundamental I e II deverá realizar um relatório, já os que possuírem conhecimento acima do Ensino Médio é necessário a realização de uma resenha (uma análise crítica do texto). Uma comissão criada pelo Estado avalia as resenhas e atribui nota, em uma escala de 0 à 10 . Para ser aprovado o relatório e a resenha devem ter nota igual ou superior à 6,0.

Em 2013, o Conselho Nacional de Justiça (CNJ) por meio da Resolução de $n^{\circ} 44$ estabelece algumas regras para que unidades federais e estaduais possam disponibilizar uma atividade complementar a leitura como remição da pena, somente presos que não são contemplados nos outros dois tipos de redução de pena podem ser beneficiados. Para ter direito à remição por esta resolução é necessário que tenha um projeto de leitura elaborado pelo estado ou pela federação, e deve oferecer um exemplar de obra literária, clássica, científica, entre outros, para cada participante.

A obra deve ser disponibilizada perante o acervo disponibilizado na unidade, esses livros serão doados pelos órgãos públicos como: Administração Penitenciária de cada estado, órgãos de execução penal, entre outros. A comissão organizadora do projeto é encarregada de avaliar o texto elaborado pelo preso de forma a analisar a resenha, logo após a nota, o material é enviado a um Juiz de Execução Penal para que seja decidido se o encarcerado realmente entendeu o assunto abordado no texto. Diferentemente da Lei paranaense, a Resolução do CNJ estipula datas e a quantidade de dias que a pessoa consegue diminuir, a saber: 
21 (vinte e um) a 30 (trinta) dias para a leitura da obra, apresentando ao final do período resenha a respeito do assunto, possibilitando, segundo critério legal de avaliação, a remição de 4 (quatro) dias de sua pena e ao final de até 12 (doze) obras efetivamente lidas e avaliadas, a possibilidade de remir 48 (quarenta e oito) dias, no prazo de 12 (doze) meses, de acordo com a capacidade gerencial da unidade prisional. (CONSELHO NACIONAL DE JUSTIÇA, 2013).

Os profissionais que participam do projeto como: pedagogo e professor de língua portuguesa devem orientar o preso a como realizar o texto avaliativo. Além do Estado do Paraná em que a remição de pena virou Lei estadual, o Distrito Federal e os estados do Maranhão, São Paulo e Rio Grande do Norte estabeleceram as leis para remição de pena pela leitura por meio de projetos de leitura, de forma que cada estado estabelece suas diretrizes. O Estado do Rio Grande do Norte e São Paulo incorporaram em suas Leis uma das regras da Portaria Conjunta de $n^{\circ} 276$, o que estabelece que o texto analisado deve seguir:

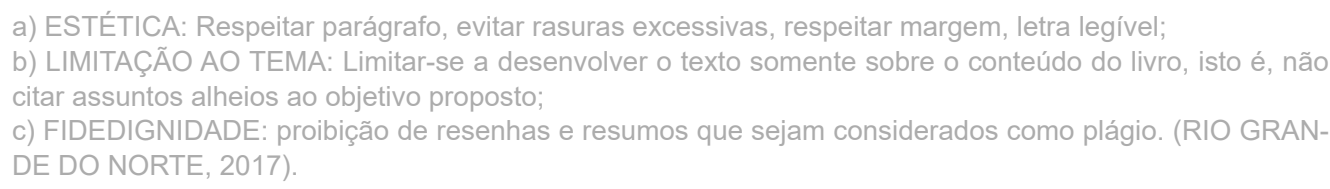

É interessante observar que o rigor e o critério na análise dos textos críticos dos presos nem sempre são observados na análise dos trabalhos dos alunos dos ensinos fundamental e médio nos sistemas estaduais de educação. O Brasil tem um Projeto de Lei 3216/2015 em que pede mudanças na LEP para o acréscimo da leitura como remição. O Estado de São Paulo teve alguns conflitos no momento da aprovação da lei entre a Assembleia Legislativa do Estado e o governador do estado. O Projeto de Lei $n^{\circ} 390$ de 2017, que virou a Lei no 16.648 de 11 de janeiro de 2018, foi construída de maneira parecida com a de outros estados em quesitos da: voluntariedade do detento em participar do projeto, o prazo para a leitura, os dias a serem apenados, entre outros. Contudo, o projeto queria liberar a remição de pena ao realizar a leitura da bíblia:

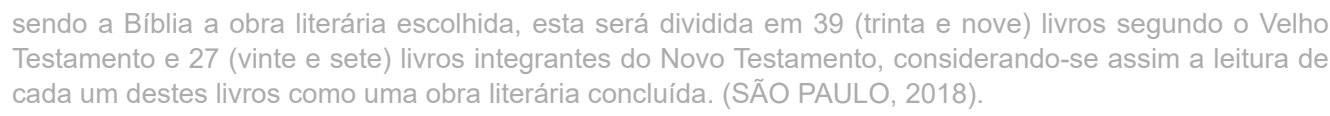

O projeto foi sancionado com somente três artigos aprovados e o restante foi vetado, porém pouco tempo depois a Assembleia Legislativa do Estado aprovou as partes vetadas. Essa decisão causou um certo desconforto pelo motivo do Estado brasileiro sendo laico, permitindo que a lei que tinha a vertente do acesso, construção do pensamento crítico se transforma em imposição de uma religião às pessoas.

A Lei no 16.686 não apresenta um projeto de leitura em si, como também deixa as unidades prisionais responsáveis pela seleção e definição de uma comissão para a avaliação dos textos. Não há critérios para a escolha dessa comissão, isto causa uma sensação de que tudo está correto, mas parando para pensar o usuário deste projeto não tem voz na escolha, já que alguns casos os livros já são delimitados pela organização da iniciativa. Segundo Bertoni (2015), o Estado de São Paulo tem uma lista com cerca de 12 títulos ${ }^{1}$ nos quais até então poderiam ser utilizados para remir a pena, entretanto com a aprovação da Lei não se tem a informação se a lista corresponde ou não com o que é disponibilizado aos apenados. O Estado do Rio de Janeiro contém um projeto de lei $n^{\circ}$ 2920/2017 ainda se encontra em fase de discussões em comissões. Os Estados do Pará e Goiás não têm leis que regulamentem a remição pela leitura, mas projetos administrados pelo poder público estadual. No Pará o projeto foi criado por defensores públicos em 2012, chamado de 'Resgatando a Dignidade pela Leitura', criado em 2012, o programa está presente em cinco unidades prisionais do estado. Neste Estado "A leitura é realizada nos encontros semanais e a produção textual ocorre 15 em dias específicos." (PARÁ, 2016). A Agência Goiana do Sistema de Execução Penal (AGSEP) criou a campanha 'Livros que Educam' em 2013, que arrecadou cerca de 85 mil livros que seriam distribuídos entre 85 novas bibliotecas implementadas pelo estado.

A remição tem como princípio os "benefícios ao seu intelecto, o que pode facilitar a o seu convívio com a sociedade após sua saída do sistema prisional." (AMARAL; SZYMANOWSKI, 2012). No entanto, para que seja alcançado esse objetivo é necessário que o sistema compreenda as graves dificuldades de recursos públicos no país.

Segundo o Levantamento Nacional de Informações Penitenciárias (IFOPEN) em seu último levantamento de julho de 2016, o Brasil tem cerca de 726.712 pessoas reclusas de liberdade, nos quais dentre os dados coletados de cerca de 482.645 , sendo $51 \%$ dessa população ainda se encontram no ensino fundamental completo ou incompleto. Ou seja, como os apenados comuns realizarão resenhas e relatórios sendo que os mesmos ainda têm dificuldades básicas de aprendizagem? "Não basta preparar um texto que atenda à proposta de remição de 
pena, é necessário permitir que o leitor se coloque, que se mostre, revele-se e construa um espaço de liberdade ao compartilhar seus pensamentos." (RIBEIRO, 2018).

Quando é dito que aqueles que não estão matriculados em iniciativas educacionais e profissionalizante tem como remir a pena pela leitura, mas será que a pessoa tem uma bagagem cultural significativa, conhecimento linguístico e argumentativo para realizar o texto, mesmo que o indivíduo coloque suas opiniões sobre a temática do livro, conseguiria se expressar de forma adequada? Segundo o Infopen (2017) cerca de 12\% da população carcerária está em projetos educacionais ou complementares, sendo $2 \%$ se encontram em projetos de leitura ou esporte, isto é, cerca de 5.486 pessoas.

Ainda é pouco o número de apenados que participam de projetos de leitura, o que acarreta alguns pontos preocupantes das políticas públicas que se encontram em crise de tal maneira que se demorou anos até o Estado brasileiro encontrar uma solução para o buraco que fica entre o preso e o acesso à informação e a leitura. "Percebe tão importante quanto ter acessibilidade ao material de leitura é ter condições favoráveis para que ela ocorra de maneira que desenvolva muito mais que o gosto, mas a paixão pela mesma." (WISNIEWSKI; POLAK, 2009, p. 4415). Não pode se esquecer que com o término dos projetos ou a não reformulação dos mesmos no quesito de possibilitar ao preso não somente a leitura em prol de reduzir a pena e sim fazer com que o preso consiga expressar seus interesses com cidadão, de maneira que um dos grandes objetivos da remição de pena é a ressocialização do indivíduo.

A dúvida que paira neste momento é sobre o ambiente informacional, pois este é restrito ao detento ou o próprio só pode frequentar em dias de atividades do projeto. Será que este local tem mobiliário adequado para a realização da leitura ou a mesma é feita em uma sala de aula ou na cela? Sabemos que os projetos abordam a criação e a evolução de competências do detento, mas não conhecemos como este processo é realizado dadas as condições do espaço. Será que utilizando somente a resolução de $n^{\circ} 44$ do Conselho Nacional de Justiça (CNJ) para que todos os estabelecimentos prisionais brasileiros sejam beneficiados com iniciativas de acesso e as bibliotecas prisionais serão implementadas em todas as unidades com espaço para a mesma. A sociedade e a área biblioteconômica devem se comprometer com o auxílio essas iniciativas com doações de livros, atividades de suporte à cultura, educação e instrução. As dúvidas e incertezas sobre o assunto, ao mesmo tempo que esse propósito promove uma mudança na concepção de leitura da pessoa e diminui significativamente a pena, não quer dizer que cumpra o papel de ressocializar o sujeito de maneira correta, possibilitando as descobertas garantidas pela leitura.

A agenda 2030 da Organização das Nações Unidas propõe 17 diretrizes para uma sociedade sustentável. O acesso a materiais de leitura como agente ressocializador entra em questão com a diretriz 16, isto é, "Promover sociedades pacíficas e inclusivas para o desenvolvimento sustentável, proporcionar o acesso à justiça para todos e construir instituições eficazes, responsáveis e inclusivas em todos os níveis" (ORGANIZAÇÃO DAS NAÇÕES UNIDAS NO BRASIL, 2015).

Porém, para tornar isso uma realidade são necessárias mudanças em diversos âmbitos sociais e políticos. De acordo com Silva (2018) "Quando o estado como o brasileiro entende Educação, Cultura, Desenvolvimento Social e Segurança Pública como gastos e não investimentos integrados/ associados, inegavelmente os resultados são nefastos para a sociedade tornando os presídios grandes laboratórios experimentais da criminalidade e violência". Algumas medidas anteriores precisam ser tomadas para que a prisão alcance seu papel ressocializador e não somente o da punição, pois em muitos estabelecimentos prisionais faltam infraestruturas e instalações mínimas para a sobrevivência humana, como também em desenvolver iniciativas de acesso à educação, leitura, especialização profissional, entre outros. Se o poder público realizar um plano no qual cumpra as leis já criadas como a de criação de bibliotecas prisionais que possam disponibilizar materiais de qualidade e promover a leitura, a cultura, o conhecimento e o lazer, além de projetos educacionais voltados à reinserção das pessoas à sociedade, aumentaria o número de apenados alfabetizados, com alto nível de fluência e interpretação textos e, que manifestem um pensamento crítico.

Cabe questionar também a formação do profissional bibliotecário tão distante dessas demandas sociais. Para que este possa assumir a sua função neste ambiente, de maneira a realizar a disseminação da informação com os apenados, respeitando suas preferências e seu perfil, devem ser ofertadas, em primeiro lugar, postos de trabalho fixos para bibliotecários nos espaços prisionais.

Os projetos de leitura devem apresentar continuidade, seguir regras unificadas por meio de uma lei federal bem 
estruturada e não somente adaptar um artigo do código penal. São necessárias etapas claras, desde a implementação, a criação de acervo (biblioteca), a participação de bibliotecários, educadores, pedagogos e psicólogos auxiliando os reclusos de liberdade na realização dos textos avaliativos, como também manutenção do espaço físico adequado.

Em um país que sofre os problemas de superlotação das instituições carcerárias e consequentes massacres, seria muito difícil pensar que um elevado nível de planejamento ocorreria no âmbito da socialização do sujeito pela prática da leitura. Outro fato que se questiona é a limitação dos títulos, pois, no contexto biblioteconômico, a limitação em um número restrito de títulos poderá produzir aquilo que se conhece como fabricação cultural ou dirigismo cultural.

\section{0 profissional da informação como mediador da informação em presídios}

Esta seção abordará a importância da formação deste bibliotecário para atuar em bibliotecas prisionais ou em atividades de incentivo à leitura e ao acesso à informação. Os códigos de ética da IFLA e do Conselho Federal de Biblioteconomia (CFB) abordam a função e o objetivo da profissão para a formação do profissional que atua em unidades prisionais. O Código de Ética da IFLA para bibliotecários e outros profissionais da informação de 2012 afirma que:

O papel das instituições e profissionais, incluindo bibliotecas e bibliotecários, na sociedade moderna, é apoiar e aperfeiçoar o registro e a representação da informação e fornecer o acesso. Os serviços de informação de interesse social, cultural e de bem-estar econômico estão no coração da Biblioteconomia e, consequentemente, os bibliotecários têm responsabilidade social.

Ou seja, biblioteca e bibliotecário devem exercer a função de disponibilizar e mediador da informação sem discriminação ou censura, mas sim por aquilo que seu usuário necessita.

A missão principal dos bibliotecários e outros profissionais da informação é assegurar o acesso à infor-
mação para todos no sentido de seu desenvolvimento pessoal e educacional, enriquecimento cultural, lazer,
atividade econômica, participação informada e reforço da democracia. (IFLA, 2012, p.2)

A função principal dos profissionais da informação é permitir meios e métodos de acesso, com o intuito de possibilitar a comunidade assistida o direito a educação, lazer, cultura, entre outros. Ele deve dar a chance do indivíduo de desenvolver e aprender novos conhecimentos a partir dos serviços disponibilizados pela instituição.

A Resolução n 207/2018 do Conselho Federal de Biblioteconomia (CRB) no qual se trata do Código de Ética e Deontologia do Bibliotecário afirma:

\footnotetext{
Art. $2^{\circ}$ - A profissão de Bibliotecário tem natureza sociocultural e suas principais características são a prestação de serviços de informação à sociedade e a garantia de acesso indiscriminado aos mesmos, livre de quaisquer embargos.

Parágrafo único - O bibliotecário repudia todas as formas de censura e ingerência política, apoia a oferta de serviços público e gratuitos, promove e incentiva o uso de coleções, produtos e serviços de bibliotecas e de outras unidades de informação, segundo o conceito de acesso aberto e universal.
}

O dever do bibliotecário enquanto profissional da informação é disponibilizar a informação não importando o seu público. A informação deve ser acessada por diversos meios sejam físicos ou digitais, porém quando se fala do sistema prisional ocorre certa negligência por parte do poder público e da área da Biblioteconomia. Como afirmam Souza e Cabral (2011, p.1878) a temática ainda não se tornou permanente em eventos que abordam atuação profissional ou em eventos da área de ciência da informação que abordam o tema ética na profissão.

Visto que a Lei 7.210 de 11 de julho de 1984 prevê a criação destas bibliotecas, mas atualmente o número de unidades é insuficiente para a demanda destas pessoas. Esta situação prova a falta de valorização do assunto pela biblioteconomia. Parece que o sujeito recluso não é pensado como uma ser racional e dotado de direitos, ou que o mesmo contém uma opinião e conhecimento que poderiam ser trabalhados.

A lógica do pensamento conservador tende a argumentar que a utilização dos recursos financeiros no Brasil deve centrar-se em pessoas ainda em formação para evitar que se desviem do caminho correto no futuro, e que aqueles que já se encontram na condição de presos devem pagar pelos seus atos e devem receber o mínimo possível do estado, não importando a situação dos presídios brasileiros. Esse pensamento no fundo defende que as condições precárias das prisões (estrutura física e sanitária deficitárias, superlotação e conflitos entre grupos 
rivais) fazem parte da própria pena. Neste caso, não são apenas os anos com restrição de liberdade importantes para o cumprimento da pena, mas o sofrimento causado pelo ambiente parece fazer parte do processo.

Temos clareza que não somente o bibliotecário resolverá os problemas educacionais dos apenados, no entanto, o mesmo ajudaria o trabalho do educador no processo de desenvolvimento intelectual do sujeito.

No Brasil ainda não existe uma lei que permita bibliotecários trabalhar em bibliotecas em prisões e muito menos um curso de especialização na área. Assim como há uma deficiência desse tema nas estruturas curriculares dos cursos de graduação de biblioteconomia. A atuação em bibliotecas nos espaços prisionais ainda não é uma realidade no sistema prisional brasileiro e tampouco existe a presença deste profissional cumprindo seu papel de educador e socializador, exceto quando existe algum projeto de extensão de curto prazo em unidades prisionais (GOMES, 2016).

Para assumir esse cargo o profissional deve ter uma bagagem socioeducativa obtida durante a graduação. 0 sujeito necessita ter uma bagagem literária e cultural diversificada, como também conter "um grande número de qualidades humanas específicas, incluindo assertividade, flexibilidade, paciência, estabilidade emocional, prestimosidade, sinceridade, alta tolerância ao estresse e senso de humor." (LEHMANN², 2011, tradução nossa).

A formação do bibliotecário que atuará em biblioteca prisional necessita de disciplinas de cunho socioeducativo, tendo em vista da "ampliação dos campos de atuação e de reformulação dos currículos de formação do bibliotecário brasileiro, que afirmamos ser cada vez mais importante que os conteúdos relativos à ética e à responsabilidade social estejam contemplados nas mais diversas disciplinas de formação do bibliotecário." (MORAES; LUCAS, 2012, p.121). Isto é, nos currículos dos cursos é necessário disciplinas que envolvam ética, estudo de usuários, comportamento informacional, disseminação da informação, disciplinas na área da educação entre outros.

\section{Considerações Finais}

A leitura possibilita "maiores e melhores condições de formular um senso crítico em relação à realidade que nos cerca, acessar aos conhecimentos das mais diversas áreas do saber, formular nossas concepções." (JOHN, 2004, p. 51). Embora tendo diversas dificuldades no processo de acesso à leitura em ambientes prisionais é interessante que ainda não foi aprovado o Projeto de Lei 2316/2015, no que ocasiona em uma não universalização das leis e projetos já existentes, de forma a possibilitar aos estados que ainda não idealizaram iniciativas o primeiro passo para o mesmo. O que não deve ser esquecido é tanto o sistema carcerário como o poder público se encontram em crise, então é equivocado criar expectativas de que somente com a remição de pena o preso será ressocializado com sucesso.

Para cumprir o artigo 16 da Agenda 2030 para o Desenvolvimento Sustentável é indispensável que o Estado Brasileiro comece a investir em medidas educacionais, sociais e culturais que beneficiem todas as unidades prisionais e não somente algumas, de modo que o acesso à educação e leitura sirva de amparo aos sujeitos privados de liberdade. A remição de pena pela leitura não será a forma mais eficaz para a ressocialização correta do indivíduo, caso não seja superada a lacuna entre os presos e o acesso qualitativo à leitura.

Além disso, a situação das bibliotecas prisionais deve ser melhorada, podendo dizer que mesmo com a iniciativa da remição pela leitura como pretexto para a criação de bibliotecas, ainda é insuficiente disponibilizar um espaço com livros sem ter o tratamento correto deste local. Uma das medidas seria uma lei que permitisse que os bibliotecários pudessem atuar nesses espaços, de maneira a ocorrer a parceria entre pedagogo, professor e bibliotecário para o desenvolvimento de atividades pedagógicas e de lazer. É crucial uma "Biblioteconomia consciente do seu papel político, social e ativo, que disponibiliza a todos o maior tesouro social da humanidade: a informação" (LINDEMANN; SPUDEIT; CORRÊA, 2016, p. 719-720). Está situação ainda é recente, e espera-se que a área da Biblioteconomia comece a se envolver com a temática, podendo contribuir no processo do acesso à informação e à leitura. 


\section{Notas}

${ }^{1}$ Lista completa de livros: $1^{\circ}$ A Arte de Ouvir o Coração - Jan-Philipp Sendker; $2^{\circ}$ A Sociedade da Neve - Pablo Vierci; $3^{\circ}$ Persépolis - Marjane Satrapi; $4^{\circ}$ Capitães de Areia - Jorge Amado; $5^{\circ}$ Admirável Mundo Novo - Aldous Huxley; $6^{\circ} \mathrm{O}$ Nome da Rosa - Umberto Eco; $7^{\circ}$ Dom Quixote - Miguel de Cervantes; $8^{\circ}$ O Processo - Franz Kafka; $9^{\circ} \mathrm{O}$ Caçador de Pipas - Khaled Hosseini; $10^{\circ}$ Abusado - Caco Barcellos; $11^{\circ}$ Diário de Anne Frank - Anne Frank e $12^{\circ}$ Estrela Amarela - Jennifer Roy.

${ }^{2}$ Original: but also a great number of specific human qualities, including assertiveness, flexibility, patience, emotional stability, helpfulness, sincerity, high tolerance for stress, and a sense of humor

\section{Referências}

AMARAL, L.M.M; SZYMANOWSKI, C. Ressocialização de presos no combate a reincidência estimulada pela leitura monitorada de livros. Direito em construção, v.3, n. 1, 2013, p.1-10.Disponível em: http://www.revista.universo. edu. br/index. phpjournal=1 direitoconstrucao3\&page=article\&op=view\&p ath\%5B\%5D=1770\&path\%5B\%5D=1191. Acesso em: 1 maio 2019.

BERTONI, E. Leitura de livros pode reduzir pena em presídios; leia a resenha feita por presos. Folha de São Paulo, 23 ago. 2015.Cotidiano, S 36-37. Disponível em: https://www1.folha.uol.com.br/cotidiano/2015/08/1672466-leitura-de-livros-pode-reduzir-pena-em- presidios-leia-resenha-feita-por-preso.shtml. Acesso em: 26 dez. 2018.

BRASIL. Câmara dos Deputados. Projeto de Lei 3216/2015. Altera o art. 126 da Lei n. 7.210, de 11 de julho de 1984 - Lei de Execução Penal, para que o condenado possa remir parte de sua pena pela leitura de obras literárias. Brasília, DF, 2015. Disponível em: http://www.camara.gov.br/proposicoesWeb/fichadetramitacao?idProposicao=1999551. Acesso em: 27 dez. 2018.

BRASIL. Conselho Nacional de Justiça. Recomendação no 44, de 26 de novembro de 2013. Dispõe sobre atividades educacionais complementares para fins de remição da pena pelo estudo e estabelece critérios para a admissão pela leitura. Disponível em: http://www.cnj.jus.br/busca-atos- adm?documento=1235. Acesso em: 30 dez. 2018.

BRASIL. Lei no 7.210, de 11 de julho de 1984. Institui a Lei de Execução Penal. Brasília, 1984. Disponível em: http://www.planalto.gov.br/ccivil 03/leis/l7210.htm. Acesso em: 26 dez. 2018.

BRASIL. Lei no 12.433, de 29 de junho de 2011. Brasil, 2011. Altera a Lei no 7.210, de 11 de julho de 1984 (Lei de Execução Penal), para dispor sobre a remição de parte do tempo de execução da pena por estudo ou por trabalho. Disponível em: http://pesquisa.in.gov.br/imprensa/jsp/visualiza/index.jsp? data=30/06/2011\&jornal=1\&pagina=1. Acesso em: 26 dez. 2018.

BRASIL, Ministério da Justiça. Departamento Penitenciário Nacional. Levantamento Nacional de Informações Penitenciárias: INFOPEN Atualização - Junho de 2016. Brasília, 2017. Disponível em: http://depen.gov.br/DEPEN/ noticias-1/noticias/infopen-levantamento-nacional-de-informacoes-penitenciarias-2016/relatorio 2016 22111.pdf. Acesso em: 27 dez. 2018.

BRASIL. Sistema Penitenciário Federal . Portaria n.276 de 20 de junho de 2012. Brasília, 2012. Disponível em: http://www.lex.com.br/legis 23454857 PORTARIA_CONJUNTA N 276 DE 20 DE JUNHO DE 2012.aspx. Acesso em: 30 dez. 2018.

CONSELHO FEDERAL DE BIBLIOTECONOMIA. Resolução 207/2018 que institui o Código de Ética e Deontologia do Bibliotecário. Brasília, 2018. Disponível em: http://www.cfb.org.br/wp- content/uploads/2018/11/Resolu\%C3\%A7\%C3\%A3o-207-C\%C3\%B3digo-de-\%C3\%89tica-e- Deontologia-do-CFB-1.pdf. Acesso em: 26 dez. 2018.

CONSELHO NACIONAL DE JUSTIÇA. Regras de Mandela: Regras Mínimas das Nações Unidas para o Tratamento dos Presos. Brasília: Conselho Nacional de Justiça, 2016. Disponível em: http://www.cnj.jus. br/files/conteudo/arquivo/2016/05/39ae8bd2085fdbc4a1b02fa6e3944ba2.pdf..Acesso em: 28 dez 2018.

GOIÁS. Superintendência Executiva de Administração Penitenciária. "Livros que Educam" e anuncia projeto para remição de pena pela leitura. Disponível em: http://www.seap.go.gov.br/noticias/agsep-lanca-livros-que-educame-anuncia-projeto-para- remicao-de-pena-pela-leitura.html. Acesso em: 30 dez. 2018. 
GOMES, L. O. A biblioteconomia como incentivo a educação e ressocialização da população carcerária: uma nova vertente do profissional bibliotecário. 2016. 69 f. Trabalho de Conclusão de Curso (Graduação) - Faculdade de Biblioteconomia, Instituto de Ciências Sociais Aplicadas, Universidade Federal do Pará, Belém, 2016. Disponível em:<http://bdm.ufpa.br/jspui/handle/prefix/26>. Acesso em:05 maio 2019.

IFLA. Código de Ética para bibliotecários e outros profissionais da informação, 2012. Disponível em: https://www. ifla.org/files/assets/faife/codesofethics/portuquesecodeofethicsfull.pdf. Acesso em: 05 jun. 2019.

JOHN, Valquíria Michela. As palavras da salvação: as representações da leitura nas prisões. 2004. 192 f. Dissertação (Mestrado) - Curso de Educação, Universidade Federal de Santa Catarina, Florianópolis, 2004. Disponível em: https://repositorio.ufsc.br/handle/123456789/87436. Acesso em: 20 dez. 2018.

LEHMANN, V. Challenges and Accomplishments in U.S. Prison Libraries. Library Trends, v.59, n.3, 2011, p. 490508.

LINDEMANN, C.; SPUDEIT, D.; CORREAA, E. Por uma Biblioteconomia mais social: interfaces e perspectivas. Revista ACB, v.21, n.3, 2016, p.707-723. Disponível em: https://revista.acbsc.org.br/racb/article/view/1211. Acesso em: 05 maio 2019.

MARTINS, M. H. O que é leitura. 9. ed. São Paulo: Brasiliense, 1988

MARINHO, R. R. Leitura: um caminho para a cidadania. Transinformação, v. 5, n.1,2,3, 1993. Disponível em: http://periodicos.puccampinas.edu.br/seer/index.php/transinfo/article/view/ 1650/1621. Acesso em: 20 dez.2018.

MORAES, M. B.; LUCAS, E. O. A responsabilidade social na formação do bibliotecário brasileiro. Em Questão, Porto Alegre, v.18, n.1, pp.109 - 124, jan./jun, 2012. Disponível em: https://seer.ufrgs.br/EmQuestao/article/ view/24107/19763. Acesso em: 30 abr. 2019.

NEVES, R. X. A leitura e o estudante de biblioteconomia: um instrumento para sua formação. Encontros Bibli: revista eletrônica de biblioteconomia e ciência da informação, Florianópolis, v. 3, n. 6, p. 1-6, jan. 1998. Disponível em: https://periodicos.ufsc.br/index.php/eb/article/view/30/56. Acesso em: 26 dez. 2018.

ORGANIZAÇÃO DAS NAÇÕES UNIDAS - BRASIL. Transformando Nosso Mundo: A Agenda 2030 para o Desenvolvimento Sustentável, 2015. Disponível em: https://nacoesunidas.org/pos2015/agenda2030/. Acesso em: 03 jan. 2019.

PARÁ. Superintendência do Sistema Penitenciário. Projeto de remição de pena, 2013. Disponível em: http://www. susipe.pa.gov.br/noticias/par\%C3\%A1-inova-ao-adotar-projeto-de-remi\%C3\%A7\%C3\%A3o-de-pena-pela-leitura-com-detentos. Acesso em: 27 dez.2018.

PARANÁ (Estado). Lei no 17.329, de 08 de outubro de 2012. Institui o Projeto "Remição pela Leitura" no âmbito dos Estabelecimentos Penais do Estado do Paraná, 2012. Disponível em: http://www.legislacao.pr.gov.br/legislacao/pesquisarAto.do?action=exibir\&codAto=77830. Acesso em: 27 dez. 2018.

RIBEIRO, M.L. P.C. Uma teia de relações: o livro, a leitura e a prisão: um estudo sobre a remição de pena pela leitura em penitenciárias federais brasileiras. 2017. 240 f., il. Tese (Doutorado em Literatura)—Universidade de Brasília, Brasília, 2017. Disponível em: http://repositorio.unb.br/handle/10482/25177. Acesso em: 28 dez. 2018.

RIO DE JANEIRO (Estado). Projeto de Lei n 2920/2017. Institui no âmbito dos estabelecimentos carcerários das comarcas do Estado do Rio de Janeiro, a possibilidade de remição de pena pela leitura. Disponível em: http:// alerjln1.alerj.rj.gov.br/scpro1519.nsf/18c1dd68f96be3e7832566ec0018d833/ a0d970e851cb713483258137005cbe53? OpenDocument. Acesso em: 26 dez. 2018.

RIO GRANDE DO NORTE (Estado). Lei n. 10.182, de 21 de fevereiro de 2017. Institui o Projeto "Remição pela Leitura" no âmbito dos Estabelecimentos Penais do Estado do Rio Grande do Norte. Disponível em: http://www. al.rn.leg.br/portal/ ups/legislacao/2019/05/14/f8d11434373dee6fa84b73426275e67d.pdf. Acesso em: 26 dez. 2018. 
SÃO PAULO (Estado). Lei de No 16.648, de 11 de janeiro de 2018. Institui, no âmbito dos estabelecimentos carcerários das comarcas do Estado, a possibilidade de remição da pena pela leitura. Disponível em: https://www.al.sp. gov.br/repositorio/legislacao/lei/2018/lei-16648-11.01.2018.html. Acesso em: 03 jan. 2019.

SILVA, J. A. Discutindo sobre leitura. Letras Escreve, v.1, n. 1, 2011, p. 22-35. Disponível em: https://periodicos. unifap.br/index.php/letras/article/view/326/n1jose.pdf.. Acesso em: 20 dez. 2018

SILVA, J.L.C. Perspectivas de atuação das bibliotecas prisionais e as contribuições para a Agenda 2030 da Organização das Nações Unidas. RBBD. Revista Brasileira de Biblioteconomia e Documentação, v.14, n.3, 2018, p. 104-122. Disponível em: https://rbbd.febab.org. br/rbbd/article/view/1060. Acesso: 03 jan. 2019

SOUZA, F. C.; CABRAL, M. R. de L. Investigação sobre a preparação do formando em biblioteconomia da ufsc para atuar em biblioteca prisional. In: XII ENANCIB - Encontro Nacional de Pesquisa em Ciência da Informação, 2011, Brasília. Anais do XII Encontro Nacional de Pesquisa em Ciência da Informação. Brasília: Thesaurus, 2011. v. 1. p. 1876-1888. Disponível em: http://repositorios.questoesemrede.uff.br/repositorios/bitstream/handle/123456789/1771/ Investigação\%20-\%20Souza.pdf?sequence=1. Acesso em: 05 maio 2019.

WISNIEWSKI, I. AP., POLAK, A. Biblioteca: contribuições para a formação do leitor. In: 9 CONGRESSO NACIONAL DE EDUCAÇÃO, 9, 2009, Curitiba. Anais... PUC-PR: Curitiba, PR. p. 4407-4419. Disponível em: http:// educere.bruc.com.br/arquivo/pdf2009/3102 1701.pdf. Acesso em: 27 dez. 2018.

YUNES, E. Pelo o avesso: A leitura e o Leitor. Letras, v.44, n.3, 1995. Disponível em: http://revistas.ufpr.br/letras/ article/view/19078/12383. Acesso em: 20 dez. 2018. 
$20 \begin{aligned} & \text { Access to reading and redemption in Brazil: a critical analysis aimed at the UN } 2030 \\ & \text { agenda }\end{aligned}$

\section{Dados dos autores}

Yara Maria Silva Cinque

Graduanda de Biblioteconomia pela Universidade Estadual Paulista "Júlio de Mesquita Filho".

cinque.yara98@gmail.com

Carlos Cândido de Almeida

Professor Doutor do Departamento de Ciência da Informação, Universidade Estadual Paulista "Júlio de Mesquita Filho"- Faculdade de Filosofia e Ciências de Marília-SP

carlos.c.almeida@unesp.br

Received: 2019-08-26

Accepted: $2020-07-31$

\section{$(\mathrm{cc})$ EY}

This work is licensed under a Creative Commons Attribution 4.0 United States License.

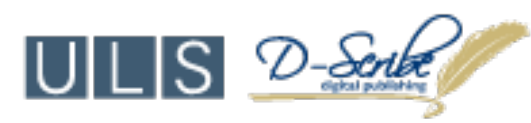

This journal is published by the University Library System of the University of Pittsburgh as part of its D-Scribe Digital Publishing Program and is cosponsored by the University of Pittsburgh Press 